\title{
Feminism and German Studies in the United States
}

Sara Lennox (Amherst)

An examination of the influence of feminist theory and scholarship on German Studies is no easy task. Perhaps more than any other methodology that has entered Inlands- and Auslandsgermanistik from without, feminist German Studies around the world reveals the strong imprint of the particular circumstances that shaped the women's movement and its academic feminist manifestations in the country out of which it emerged. Indeed, the case of feminist German Studies exemplifies in nuce why the different conditions of various countries make it necessary to write histories of the quite different trajectories pursued by Germanistik im Ausland - as splendidly illustrated in the recent volume German Studies in the United States: A Historical Handbook, edited by Peter Uwe Hohendahl. ${ }^{1}$ In this essay, I briefly trace the course of U.S. academic feminism and then look at the ways in which it entered German Studies. Then I turn to some yet unsolved problems that feminist scholars of German cultural studies confront and make some proposals for the directions that feminist cultural analysis might wish to move in the future.

To understand U.S. feminism in the twenty-first century, as well as differences between American, German, and Australian feminism from the outset of the women's movement until today, it is necessary to turn to the moment of feminism's emergence. In the United States, the women's movement that began in 1967-68 understood itself to be in alliance with other sixties movements, critical of the sexism of the student anti-war movement and the Civil Rights movement but otherwise generally in accord with their aims. At its outset, the U.S. women's movement was thus a socially critical oppositional movement that was not focused on women's issues alone. Early U.S. feminists maintained that women were fundamentally like men, and their earliest political activities were directed against the sexist treatment of women and discrimination against them in

\footnotetext{
${ }^{1}$ Peter Uwe Hohendahl (ed): German Studies in the United States: A Historical Handbook. New York: The Modern Language Association of America 2003.
} 
arenas in which men dominated. These early emphases of U.S. feminism made little impact on West Germany, where feminism did not emerge until half a decade later. By the mid-seventies, however, the U.S. women's movement had undergone a huge ideological transformation that also left its imprint on Germany: now feminists emphasised women's difference from, possibly even superiority to, men. "Radical" or "cultural" feminists argued that women's specificity - that of all women, which was taken to be the same everywhere - had been repressed within male-dominated history and culture. Feminist scholars now set about to uncover what had been obscured, hidden from history, in the past and to elaborate women's difference in the present. The texts of French theorists Hélène Cixous, Luce Irigaray, and Julia Kristeva were used to support the radical feminists' contention that female otherness, variously understood as derived from the otherness of the female psyche, anatomy, or desire, must now be allowed to speak.

What saved American feminists from what seems now an entirely untenable position were the vigorous protests of U.S. feminists of colour in a series of contentious conferences and in influential anthologies during the period from 1979 to 1982/3. U. S. feminists of colour argued, first, that what (white, middle-class) U.S. feminists had taken to be representative of all women in fact described only their own white, middle-class selves, and, secondly, that white, middle-class women could not credibly argue that all the crimes of civilisation were men's fault alone, in which women played no part and for which they bore no responsibility. In Donna Haraway's words: "White women [...] discovered (that is, were forced kicking and screaming to notice) the non-innocence of the category 'woman."'2 U.S. feminist scholars' far-reaching reconceptualisation of their field in the eighties can be understood as their effort to repudiate their essentialising views of "woman" and elaborate a methodology that would allow them to reconceive the female subject as "shifting

\footnotetext{
2 Donna Haraway: Simians, Cyborgs, and Women: The Reinvention of Nature. New York: Routledge 1991, 157.
} 
and multiply organised across variable axes of difference,"3 that is, to understand and describe how actual women differed across time and culture. If a certain appropriation of poststructuralism had allowed American (and German) feminists of the seventies and early eighties to view the stark binary opposition between men and women as the single difference founding a singular, monolithic "phallocentric" system that had excluded women from discourse and power, American feminists now turned instead to critiques of universalising paradigms, singular histories, and unitary identities elaborated by poststructuralist men. That appropriation of French theory was often inflected or modulated by attentiveness to historical specificity enabled by German Critical Theory, British neo-Marxism and Cultural Studies, and/or postcolonial theory. The origins of the new approach, which produced a transformation of American feminist scholarship without parallel in Germany, are thus multinational and a consequence of multiple theoretical displacements: as de Lauretis has put it, "feminist theory came into its own, or became possible as such [...] in a postcolonial mode."

This is the moment at which gender studies emerged in the American academy. In the United States, at least, gender studies was not understood in opposition to feminist or women's studies, but rather as a signal that the categories "woman" or "femininity" were now to be conceived differently. Though the term "gender," used to designate the social organisation of sexual difference as distinct from the biological raw material of "sex," had already entered the American feminist vocabulary by the mid-seventies, attention to ethnic specificity in scholarship of the eighties and nineties made it possible for feminists entirely to repudiate what Linda Nicholson has called "biological foundationalism," to recognize "that we cannot look to the body to ground cross-cultural claims about the male-female distinction," and to investigate the production of the sexed body across time and culture. From the mid-eighties onward, American

\footnotetext{
${ }^{3}$ Teresa de Lauretis: "Eccentric Subjects: Feminist Theory and Historical Consciousness." Feminist Studies 16.1 (Spring 1990): 116.

${ }^{4}$ De Lauretis: "Eccentric Subjects," 131.

5 Linda Nicholson: "Interpreting Gender." Signs 20.1 (Autumn 1994): 83.
} 
feminists increasingly treated masculinity and femininity as unstable and constantly changing products of historically and culturally specific social practices, always inflected by all of any culture's other symbolic categories and other modes of cultural, political, and economic organisation, varying racially, ethnically, by class and religion and for many other reasons. As feminist scholars sought new paradigms for their new understanding of gender, they turned increasingly to Foucauldian theory to formulate their understanding that, in de Lauretis's words, "gender is not a property of bodies or something originally existent in human beings, but 'the set of effects produced in bodies, behaviours and social relations,' in Foucault's words', by the deployment of 'a complex political technology." "7 Recognising that they themselves were also the products of the social categories and conditions that constructed them, American feminists also conceded their own implication in structures of power and gave up their claim to speak for all women. U.S. feminists now acknowledged that the term "women" at best described a hybrid grouping linked only by tenuous and provisional coalitions. They argued instead for new conceptions of feminist political practice that would free the category "woman" from any stable referent and allow it to be reconfigured anew in each instance, while they simultaneously advanced a conception of feminist "positionality" to describe the specific location from which particular women can act and speak. Contemporary U.S. feminists often describe their method as an "integrative analysis," within which all social categories are equally weighted (i.e. gender is merely one category among others) and constitutive rather than additive, so that any particular gendered phenomenon can be understood only if all the factors operating to produce it are taken into account. By the nineties, the new queer movement that emerged in the wake of the AIDS crisis together with Judith Butler's enormously influential theoretical texts succeeded entirely in detaching gender from biology altogether (even sometimes postulating that biological sex itself was a discursive construction), raising ever more difficult questions about whom feminist activists should regard as allies.

\footnotetext{
${ }^{6}$ Michel Foucault: History of Sexuality. New York: Vintage 1980.

${ }^{7}$ Teresa De Lauretis: Technologies of Gender: Essays on Theory, Film, and Fiction. Bloomington: Indiana University Press 1987, 3 citing Foucault, 127.
} 
The somewhat paradoxical consequence in the U.S. was a feminist movement fallen on hard times in a period of general political quiescence at the same time that gender became an ever more self-evident category of analysis in many American academic settings.

Feminism's astonishingly successful entry into the U.S. academy, as well as academic feminism's impact on U.S. German Studies, can also only be understood via a consideration of U.S. national specificities. First, some significant differences between American higher education and that of Germany and Australia made it possible for feminism more easily to gain a foothold there in the United States. The U.S. has many more colleges and universities than other industrialised countries. Though all are certainly not equal in quality or status, the respective prestige of those institutions is plotted as a continuum rather than as the rupture conceived to exist, say, between the German university and the German Gymnasium, and faculty members with a doctorate at any institution of U.S. higher education hold the same ranks, Assistant, Associate, or Full Professor. Thus from the outset feminist scholars in the United States have had more opportunities to attain a professorial position than in other countries, and if they acquire the necessary credentials (usually via publications), they can also move from an institution of lower to one of higher prestige. In addition, federal "affirmative action" policies instituted in the early seventies meant that colleges and universities faced the choice of hiring more women and minorities or potentially losing their federal funding, and many of the first feminists entered the academy as affirmative action hires. Finally, many colleges and university are privately funded and compete with each other to attract the most talented students, while the funding of departments in both public and private institutions is also often linked to the size of their enrolment figures. Hence, administrators at all levels are constrained to offer courses of study that students want, and over the past thirty years students have increasingly demanded courses focused on gender and other feminist issues. The market is thus also responsible for feminists' initial entry and ongoing presence within the academy. 
Secondly, as a consequence of the presence and influence of refugees from Hitler's Germany (and the Economic Miracle) within U.S. German Departments, American Germanistik itself may be a more liberal field in the United States than in Germany or Australia (though those refugees often enough oriented themselves primarily towards Germany and did not involve themselves in American intellectual life). German exiles educated my own generation, the graduate students of the sixties, who as a consequence frequently found (as at my own graduate institution, in the sixties and seventies often termed "das rote Wisconsin") that they could reconcile their left-leaning political commitments with a career in German literary studies. Moreover, as U.S. higher education confronted its first financial crisis in the early seventies, German Departments discovered that, to maintain high enough student enrolments to justify adequate funding, they were forced to hire U.S.-trained Ph.D.'s rather than young scholars from Germany or elsewhere, since it was essential that their instructors possessed the skills to attract and retain American undergraduates. Though the number of available academic positions certainly contracted from the seventies onward, it was not at all impossible for a quite politicised generation of young Germanists (whose female, and sometimes male, members became our field's first feminists) to be hired into permanent positions in U.S. German Departments.

Finally and probably most crucially, the organisation Women in German, founded in 1974 at a Washington University conference on the literature of the German Democratic Republic (and subsequently based for some years at "das rote Wisconsin"), has been an enormously important force within the field of U.S. German Studies. Of course the young and not quite so young U.S. women who comprised U.S. German Studies' first feminists had constructed their own professional identities vis-à-vis the German literature and culture that they studied. However, from the outset, the structures WIG put into place to support Germanistinnen in the academy were very pragmatic and very American, quite different from the relatively free-floating, mostly intellectual, and highly European-identified Marxist Germanists to whom the new feminists also felt affinities. From its outset, WIG has attempted to devise "hands-on" 
strategies to bridge the many divides that rend the academy. In contrast to other areas of feminist scholarship, senior feminists within German Studies are not only WIG members, but enthusiastic participants in its meetings. Senior women take very seriously their task of educating and nurturing the Nachwuchs and at yearly WIG conferences have arranged numerous WIG panels addressing pedagogical techniques; interview skills; syllabus, c. v., and teaching and tenure dossier preparation; journal and book publishing; grant applications; and many other topics. Together with its challenges to academic hierarchy, WIG also acknowledges the connectedness of the personal and the professional. Each conference begins with a panel focused on the intersection of personal and professional issues, and in general the conference provides older and younger feminist Germanists with a brief respite from the "balancing act" of juggling numerous incompatible obligations and comforts and sustains WIG members in departments hostile to feminism (whose numbers, happily, have declined over the years). In this regard WIG also carries on the peculiarly American feminist politics of the early U.S. women's movement by holding two mutually contradictory positions at the same time, both agitating as liberals for feminists' integration into the academy as it presently exists and simultaneously advocating for far-reaching qualitative changes in all of society that would enable the transformation of both women and men. As Jeanette Clausen observed as long ago as $1984,{ }^{8}$ WIG members conceive WIG to be a concrete utopia, a site where they can begin to realise their visions and reflect upon goals that extend beyond the immediately pressing problems of their daily lives. WIG's principled and ongoing commitment to a kind of solidarity that early U.S. feminists might have termed "sisterhood" begins to explain how and why feminist German Studies has often played a highly salutary role within U.S. German Departments and our discipline in general.

\footnotetext{
${ }^{8}$ Jeanette Clausen: "Sieben Jahre, Women in German: An- und Widersprüche einer feministischen Germanistik in den USA." Feministische Literaturwissenschaft: Dokumentation der Tagung in Hamburg vom Mai 1983. Inge Stephan and Sigrid Weigel (eds.), Berlin: Argument 1984. 143-165.
} 
But, though WIG has helped U.S. feminist Germanists over the years to preserve the best aspects of the early U.S. women's movement, in their theoretical approaches to German literature WIG members have very much changed with the times, mainly following the lead of feminists in other areas of the U.S. academy. First focusing on the analysis of sexism in literary texts inaugurated by Kate Millett's Sexual Politics (1971), ${ }^{9}$ feminist Germanists also swiftly seized upon another familiar standby of feminist scholarship, "Images of Women in the Works of [...]" Because WIG was not founded until 1974, such early variants of feminist analysis coexisted with approaches more in vogue in the mid-seventies, and WIG's first conferences also undertook the resurrection of "lost" women authors and the reinterpretation of those better known. By the late seventies WIG members too insisted on the fundamental difference of women from men and saw their task as the retrieval and elaboration of an autonomous female culture that patriarchal domination had hitherto repressed. However, the U.S. feminist attention to differences among women provoked a strong reaction in WIG members, too. Within feminist German Studies, this new understanding of the importance of differences among women crystallised around two events. First, at the WIG conference in 1979 it became apparent that a great many WIG members were Jewish, thus had a very complex relationship to the German culture they taught and could not be conceived to be simply women tout court. Somewhat later, Claudia Koonz's book Mothers in the Fatherland: Women, the Family, and Nazi Politics (1987) ${ }^{10}$ argued that, while German women were indeed subordinated to men under National Socialism, their support for Nazism was nonetheless crucial to its success. Indeed, Koonz argued, German women were not only not the Nazis' innocent victims, but often enough enthusiastic supporters of National Socialism themselves. By the mid-eighties, a significant disparity could be identified between the positions of feminist Germanistinnen in Germany and American feminist Germanists: while the Germans continued to explore the relevance of French feminist theory for women and representation, many

\footnotetext{
${ }^{9}$ Kate Millett: Sexual Politics. London: Sphere Books 1971.

${ }^{10}$ Claudia Koonz: Mothers in the Fatherland: Women, the Family, and Nazi Politics. New York: St. Martin's Press 1987.
} 
Americans found the theory depoliticising in its inability to conceptualise women's differences from each other and its refusal to look at specific women in specific circumstances. It is striking that "Weiblichkeit" remained the central term of German feminist investigation long after "femininity" had been replaced by "gender" in U.S. analyses. By the nineties, as the discipline of history negotiated its "linguistic turn" and Foucault's influence became more prominent throughout the U.S. academy, history and theory (and, perhaps more slowly, German and American feminists) reconverged in the investigations of historically specific manifestations of gender and sexuality, now understood as always also discursive productions. WIG members now drew upon a range of methodologies elaborated outside of Germanistik to investigate the ways in which gender manifests itself, and, as an insistence on the discursive construction of all human experience gradually dismantled the distinction between literary texts and other cultural productions, also turned their attention to a wide range of cultural phenomena beyond the mainstream or even the feminist literary canon.

Nor was the influence of these methodological transformations upon U.S. German Departments limited to the terrain of gender studies alone. On the contrary: it seems likely that U.S.-trained feminist Germanists bear major responsibility for importing into U.S. German Studies the range of methods and emphases first elaborated in feminist and other areas of Anglo-American literary and cultural studies. In that respect, the "Americanisation" and "feminisation" of our field, variously lamented or hailed in the eighties and nineties ${ }^{11}$ as an older generation of Germantrained Germanists was replaced by younger, U.S.-trained, and frequently female scholars, was responsible for a transformation of the discipline that increasingly distinguished it from German Germanistik. In the eighties and nineties, many American German Departments were rent by bitter conflicts over the future contours of the field, but by the late nineties the German Studies approach had won the day, as the German Studies Association's "Guidelines for Curricula in German Studies at

${ }^{11}$ Cf. Valters Nollendorfs: "Out of Germanistik: Thoughts on the Shapes of Things to Come." Unterrichtspraxis 27.1 (1994), 1-10. 
Universities and Colleges in North America," formulated in 1998, indicate:

This variety of German Studies represented a shift from the philological focus of German Germanistik to a broader concentration on culture studies, often with the help of methods derived from Anglo-American literary studies (cultural studies, new historicism, film studies, feminism, ethnic and minority studies, gay and lesbian studies, queer theory, postcolonial theory). Originating as an oppositional movement led by younger Germanists attempting to challenge older approaches, this version of German Studies has achieved widespread acceptance in the field. ${ }^{12}$

The German Studies Association itself, an interdisciplinary organisation that brings together scholars from all fields that focus on "things German," has also played a role in expanding German cultural studies beyond the parameters of German Germanistik, giving cultural studies scholars in German easy access to scholarship and scholars in history and the social sciences.

What problems does U.S. feminist German Studies, does American German Studies as a field, now confront? In my view, our field now faces three major unresolved issues. First, it appears to me that no scholars of literary and cultural studies, including U.S. feminist Germanists, have successfully solved the problem of how to undertake scholarship that is genuinely interdisciplinary. To be sure, from its outset all feminist scholarship has insisted on the necessity of its own interdisciplinarity, since it ultimately seeks to examine all aspects of all women's lives in every time and culture, and certain kinds of interdisciplinarity also characterise recent scholarship produced by scholars trained in former departments of German literature, as the 1995 "Editorial Introduction" to the "Special Survey; German Studies Programs and Courses" of Monatshefte, a leading journal of U.S. German Studies, notes: "Even a reading of

\footnotetext{
${ }^{12}$ German Studies Association. "Guidelines for Curricula in German Studies at Universities and Colleges in North America." www.g-s-a.org.
} 
dissertation titles in our annual listings indicates, at least to literary scholars brought up in the 1950s and 1960s, an almost total change in paradigm. Pure study of literature seems to be the exception now, rather than the rule." 13 However, in my opinion, such observations mean only that our own discipline has changed, not that we scholars of German Studies, feminist or otherwise, have metamorphosed into experts in some other fields. During our frequent discussions of interdisciplinarity at WIG conferences, WIG members constantly express their anxiety about their lack of in-depth training in the methods of other disciplines as well as their inability to remain abreast of scholarly developments that would be required in serious research integrating the field's newest insights. Many WIG members would likely answer the question posed by Frank Trommler - "Is Interdisciplinarity Really So Hard to Do?"14 - with a resounding "Yes!" But German Studies cannot continue to mean, as GSA members have frequently quipped, that historians, political scientists, and Germanists meet in adjoining rooms at the annual GSA convention. If this is a project worth undertaking, if the study of women indeed demands engagement in a range of disciplines, then we need to devise mechanisms to enable that encounter. Women in German has frequently focused its conferences on questions of interdisciplinarity; I would argue that disciplinary encounters must continue to be foregrounded by WIG and by other organisations in our field, especially the German Studies Association. We need also to propose other joint panels, joint conferences, joint research projects that allow us to probe the limits and porosity of our fields, preferably via specific projects that allow us concretely to investigate incongruities between the disciplines. Optimally graduate students should receive a master's or graduate minor's level of training in at least one other discipline, while more advanced scholars would optimally receive (foundation- or institution-funded) research leaves that send them back to school to bone up on another field. Until such projects are

\footnotetext{
${ }^{13}$ Editorial Introduction. "Special Survey: German Studies Programs and Courses." Monatshefte 87.3 (1995), 350-66, here 360.

${ }^{14}$ Frank Trommler (ed.): "The Future of German Studies or How to Define Interdisplinarity in the 1990s." German Studies Review. 15.2 (May 1992), 201-18, here 210.
} 
accomplished, I would urge extreme caution in making the claim that we are in fact engaged in interdisciplinary German Studies, feminist or other.

Secondly, I would like to argue that in feminist German Studies (and elsewhere in cultural studies), we have not yet devised a methodology that allows us to undertake such interdisciplinary projects; no area of feminist cultural studies has formulated a method that, beyond the proposals of a now obviously inadequate Marxism, could connect areas that Marxism used to term "superstructure" and "base," or even to talk adequately about the relationship between the two. In my view, British Cultural Studies (which after all originated in the field of sociology), or a related feminist variant, sometimes called "materialist feminism," may provide the best entry point for feminist and other scholars attempting to elaborate new methods that would allow them to draw upon results arrived at in many disciplines. Cultural Studies has understood itself from the outset as an interdisciplinary method; as the collection Introducing Cultural Studies puts it:

Cultural studies is not a discipline. It is, in fact, a collective term for diverse and often contentious intellectual endeavors that address numerous questions, and consists of many different theoretical and political positions. That is why cultural studies is often described as an 'anti-discipline' - a mode of inquiry that does not subscribe to the straitjacket of institutionalized discipline. ${ }^{15}$

Moreover, Cultural Studies understands cultural products as always intertextual, patched together out of preexisting discourses, thus often internally contradictory, a site at which dominant conceptions could be articulated but also a location for subversion and opposition. And finally, Cultural Studies maintains that cultural products are always polysemic, that is, possess multiple meanings that can be activated in different ways by different kinds of audiences inhabiting different social locations. The different positionalities of their viewers, listeners, readers, etc., cause

\footnotetext{
${ }^{15}$ Ziauddin Sardar, Borin Van Loon and Richard Appignanesi (eds.), Introducing Cultural Studies. $2^{\text {nd }}$ ed. Toronto: Totem Books 2001, 8.
} 
them to stress elements of the cultural product that may variously accord with (aspects of) the ruling order or draw it into question. Cultural Studies thus authorises feminist and other oppositional scholars to emphasise aspects of cultural products in contradiction to the dominant order of the era when the text was produced or current hegemonic practices and provides a methodological justification for the engaged stance that feminist scholars wish to assume.

"Materialist feminism," a method that does not pertain to the investigation of cultural production alone, may comprise a further step in the direction of a genuinely interdisciplinary method for feminist German Studies. The method of materialist feminism first emerged in the late seventies, often designating efforts to turn Marxist-derived methods to feminist ends, but by the nineties the term had come to refer to a methodology that combined post-Althusserian Marxism with postmodern discourse theories. Practitioners of this approach intend the adjective "materialist" to indicate their method's indebtedness to Marxism - but simultaneously also to mark its distance from any of Marxism's orthodox varieties and to denote its refusal to construe the economic sphere as the prime mover of social change even "in the last instance." As well, the term "materialist" indicates the method's commitment to understanding the interconnections between discursive or signifying practices and nondiscursive forces and events that may influence cultural production. Materialist feminists insist that discourse/ideology cannot be detached from material practices and conditions or even, except perhaps heuristically, be understood as separate "spheres" at all (in the manner of the old base/superstructure division). Rather, all social practices are "overdetermined," and all elements of the social order inflect and influence each other in complex and unpredictable ways. Signifying practices are thus imbricated within the historically-specific social relations that produce them and that they (dialectically) help to produce, and a materialist feminist reading strategy takes the form of ideology critique, probing texts to discover how they work to support, document, and/or challenge the existing social order. Materialist feminism still confronts many unanswered methodological questions (and its adherents are 
inclined to fall back into outmoded Marxist stances when they confront methodological conundrums they cannot yet resolve). However, because materialist feminism has at least thematised the problem of how to analyse the interconnectedness of various social realms, it may provide a route that feminist Germanists can traverse as they move towards a solution to the problem of how to undertake genuine interdisciplinarity.

Finally, feminist Germanists confront an issue that will demand great soul-searching on the part of many disciplines within the U.S. academy and beyond. The devastations produced by over five hundred years of "globalisation," i.e. of incursions by Western powers into non-Western parts of the globe, increasingly compel feminists and others to ponder to what degree their own scholarship may also finally rest on premises also presupposing the superiority of the West. As feminists earlier understood that it is quite impossible to "shed" the structures of a masculinist society to return to a sphere of uncontaminated femininity, so likewise we now must recognise that we cannot escape Eurocentrism by retreating to terrains construed to be "outside" its sway; some other strategies will be necessary. Nonetheless, Europeanists and feminists have been startlingly absent from discussions about challenges to Eurocentrism, as scholars whose work focuses on non-Western countries have advanced the startling claim that scholarly opposition to globalisation necessitates a fundamental rethinking of many intellectual paradigms that derive from European modernity. In my view, our charge is the elaboration of a postEurocentric conception of Europe would entail "provincializing Europe," to use Dipesh Chakrabarty's felicitous phrase, ${ }^{16}$ displacing Europe itself from its central role on the world-historical stage and European paradigms from their claim to comprehend all of human experience - while we nonetheless continue to insist on the importance of European society and culture, though now only as one locus among many. A postEurocentric perspective on Europe might make it possible for feminists to construct a quite different version of European history and culture than the one that has hitherto been transmitted to us.

\footnotetext{
${ }^{16}$ Dipesh Chakrabarty: Provincializing Europe. Princeton, NJ: Princeton University Press 2000.
} 
Should feminist Germanists wish to understand Europe via the postEurocentric optic enabled by globalisation, we must certainly concede that we can no longer study areas of the world in isolation from one another, or more specifically for our purposes, to produce knowledge about Germany and Europe that does not situate each within its global context. Instead, we must understand Europe (and the individual regions of Europe) as both influenced by and influencing events that happen elsewhere in the world. That is a problem for scholars of all national literatures, who are rarely trained in cultures other than the one they study, and a particular dilemma in German Studies, where scholarship in many areas has tended to pause at Germany's borders and where, due to Germany's short colonial history, the rest of the world may be present in German cultural products only in very coded traces or even only in the cultural product's gaps and absences, in that about which it cannot or will not speak. More grandly, a post-Eurocentric paradigm may demand that Western scholars recognise that the European-derived categories which "we" have taken to be universal are merely expressions of a specific particularism that has proclaimed itself to be universal and at least since 1492 has possessed the global power to enforce that claim. Notions of the individual, of the division between public and private, of gender and sexuality taken to be universal now call for further interrogation. Progress, modernity, development, and the formation of the nation-state and its citizen-subjects, including the emancipation to which women have aspired, must be probed to discover their utility in a post-Eurocentric context. Such questioning would seem the purview of feminist theorists, who played a leading role in advancing critiques of universalising categories as they attempted to acknowledge differences among women, and certainly postmodern feminists' critiques of universalism often include the obligatory descriptor "Western," but no feminist thinker that I know has troubled to investigate alternative epistemological models exterior to Europe. I know no feminist scholarship that investigates how Europe, or more generally the "developed world" itself, might be differently understood via the lens of a post-Eurocentric perspective. Very little feminist work even explores globalisation's obvious impact on First World women, analyses urgently necessary if feminists are to elaborate their 
own agendas within the burgeoning anti-globalisation movement. It might be possible even to contend that U.S. feminist scholars' failure to theorise such issues might play some role in American feminism's current malaise, for we have neglected to explore how global social and economic arrangements damage not just women of the underclass, of colour, and of the South, but also apparently privileged women in the U.S. (and Germany) very like ourselves.

Yet for over thirty years, U.S. feminist Germanists have taken the lead in introducing new issues into German Studies, and these new tasks are also ones from which WIG members surely will not shrink. Women in German as an organisation has rightly prided itself that its members have been in the forefront of efforts to interrogate German constructions of otherness, to challenge Germans' conception of themselves as inhabitants of a monocultural country, to make the literary and cultural productions of ethnic minorities in Germany a visible presence within German Studies, to draw into question the ethnic bases of the German literary canon, and to investigate the relevance of German colonialism for German identity construction in the present. Whether they choose a materialist feminist approach or some other, many feminist scholars in U.S. German Studies now use the critical perspective they honed in their gender-based scholarship to address both gender and other German topics they may now believe to be of great political or ethical urgency. With feminists in the forefront, American Germanists believe that our different perspective allows us to pose questions - regarding gender, multiculturalism, colonialism and postcoloniality, heterogeneity and particularism, the meaning and functionalisation of Germany's past, and the role of the nation in a globalising world, among many other things - that German Germanistik and other areas of German scholarship have too seldom stepped forward to address. Those are positions at which, without the contributions of American feminists, the discipline of U.S. German Studies might otherwise never have arrived, and there is every likelihood that the creative contributions of U.S. feminist Germanists will continue to transform our field. 